\title{
MANIFESTO 2000 POR UMA CULTURA DE PAZ E NÃO VIOLÊNCIA
}

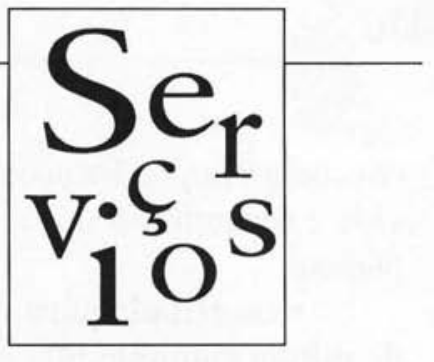

A intenção que motiva a publicação do Manifesto 2000 em português, espanhol, francês e inglês na seção Serviços é a de indicar ao leitor de Comunicação \& Educação o importante compromisso que cada cidadão tem com o futuro, propondo, inclusive, que cada um subscreva $o$ Manifesto e tome para si a tarefa de buscar a transformação profunda de que a sociedade tanto necessita.

O Manifesto 2000 para uma cultura de paz e não violência foi formulado por personalidades premiadas com o Nobel da Paz, com o objetivo de chamar a atenção do indivíduo para que ele assuma sua responsabilidade em relação a essa questão. Não é um chamamento, nem uma petição dirigida a instâncias superiores. Ele chama a atenção para a responsabilidade de cada ser humano de converter em realidade os valores, a atitude, os comportamentos que fomentam a cultura e a paz. Porque cada um pode atuar no marco de sua família, de sua localidade, de sua cidade, de sua região e de seu país, praticando e fomentando, no dia-a-dia, a não-violência, a tolerância, o diálogo, a reconciliação, a justiça e a solidariedade.

Em Paris, em 4 de março de 1999, o Manifesto 2000 se fez público e se propôs a colher adesões através do mundo.

O objetivo é o de reunir 100 milhões de assinaturas ao amanhecer do Terceiro Milênio, quando terá lugar a Assembléia Geral das Nações Unidas, em setembro do ano 2000 .

\section{TEXTO INTEGRAL DO MANIFESTO $2000^{1}$}

Reconhecendo minha parte de responsabilidade ante o futuro da humanidade, especialmente para as crianças de hoje e de amanhã, me comprometo, em minha vida diária, em minha família, no meu trabalho, na minha comunidade, em meu país e minha região a:

- respeitar a vida e a dignidade de cada pessoa, sem discriminação nem preconceitos;

- praticar a não-violência ativa, rechaçando a violência em todas as suas formas: física, sexual, psicológica, econômica e social, em particular em defesa dos mais fracos e vulneráveis, como as crianças e os adolescentes;

- compartilhar meu tempo e meus recursos materiais cultivando a generosidade a fim de acabar com a exclusão, a injustiça e a opressão política e econômica;

- defender a liberdade de expressão e a liberdade cultural, privilegiando sempre a escuta e o diálogo, sem ceder ao fanatismo, nem à maledicência e ao rechaço do próximo;

- promover um consumo responsável e um modo de desenvolvimento que leve 
em conta a importância de todas as formas de vida e o equilíbrio dos recursos naturais do planeta;

- contribuir para o desenvolvimento de minha comunidade, propiciando a plena participação das mulheres e o respeito aos princípios democráticos, com o fim de criarmos juntos novas formas de solidariedade.

\section{MANIFIESTO 2000 POR UNA CULTURA DE PAZ Y NO VIOLENCIA}

Reconociendo mi parte de responsabilidad ante el futuro de la humanidad, especialmente para los niños de hoy y de mañana, me comprometo en mi vida diaria, en mi familia, mi trabajo, mi comunidad, mi país y mi región a:

- respetar la vida y la dignidad de cada persona, sin discriminación ni prejuicios;

- practicar la no violencia activa, rechazando la violencia en todas sus formas: física, sexual, psicológica, económica y social, en particular hacia los más débiles y vulnerables, como los niños y los adolescentes;

- compartir mi tiempo y mis recursos materiales cultivando la generosidad a fin de terminar con la exclusión, la injusticia y la opresión política y económica;

- defender la libertad de expresión y la diversidad cultural privilegiando siempre la escucha y el diálogo, sin ceder al fanatismo, ni a la maledicencia y el rechazo del prójimó;

- promover un consumo responsable y un modo de desarrollo que tenga en cuenta la importancia de todas las formas de vida y el equilibrio de los recursos naturales del planeta;

- contribuir al desarrollo de mi comunidad, propiciando la plena participación de las mujeres y el respeto de los principios democráticos, con el fin de crear juntos nuevas formas de solidaridad.

\section{MANIFESTE 2000 POUR UNE CULTURE DE LA PAIX ET DE LA NON-VIOLENCE}

Conscient de ma part de responsabilité face à l'avenir de l'humanité, et en particulier des enfants d'aujourd'hui et de demain, je prends l'engagement dans ma vie quotidienne, ma famille, mon travail, ma communauté, mon pays et ma région, de:

- respecter la vie et la dignité de chaque être humain sans discrimination ni préjugé;

- pratiquer la non-violence active, en rejetant la violence sous toutes ses formes: physique, sexuelle, psychologique, économique et sociale, en particulier envers les plus démunis et les plus vulnérables tels les enfants et les adolescents;

- partager mon temps et mes ressources matérielles en cultivant la générosité, afin de mettre fin à l'exclusion, à l'injustice et à l'oppression politique et économique;

- défendre la liberté d'expression et la diversité culturelle en privilégiant toujours l'écoute et le dialogue sans céder au fanatisme, à la médisance et au rejet d'autrui;

- promouvoir une consommation responsable et un mode de développement qui tiennent compte de l'importance de toutes les formes de vie et préservent l'équilibre des ressources naturelles de la planète;

- contribuer au développement de ma communauté, avec la pleine participation des femmes et dans le respect des principes démocratiques, afin de créer, ensemble, de nouvelles formes de solidarité.

\section{MANIFESTO 2000 FOR A CULTURE OF PEACE AND NON-VIOLENCE}

Recognising my share of responsibility for the future of humanity, especially for today's children and those of future generations, I 
pledge - in my daily life, in my family, my work, my community, my country and my region - to:

- respect the life and dignity of every person without discrimination or prejudice;

- practise active non-violence, rejecting violence in all its forms: physical, sexual, psychological, economical and social, in particular towards the most deprived and vulnerable such as children and adolescents;

- share my time and material resources in a spirit of generosity to put an end to exclusion, injustice and political and economic oppression;
- defend freedom of expression and cultural diversity giving preference always to dialogue and listening rather than fanaticism, defamation and the rejection of others;

- promote consumer behaviour that is responsible and development practices that respect all forms of life and preserve the balance of nature on the planet;

- contribute to the development of my community, with the full participation of women and respect for democratic principles, in order to create together new forms of solidarity.

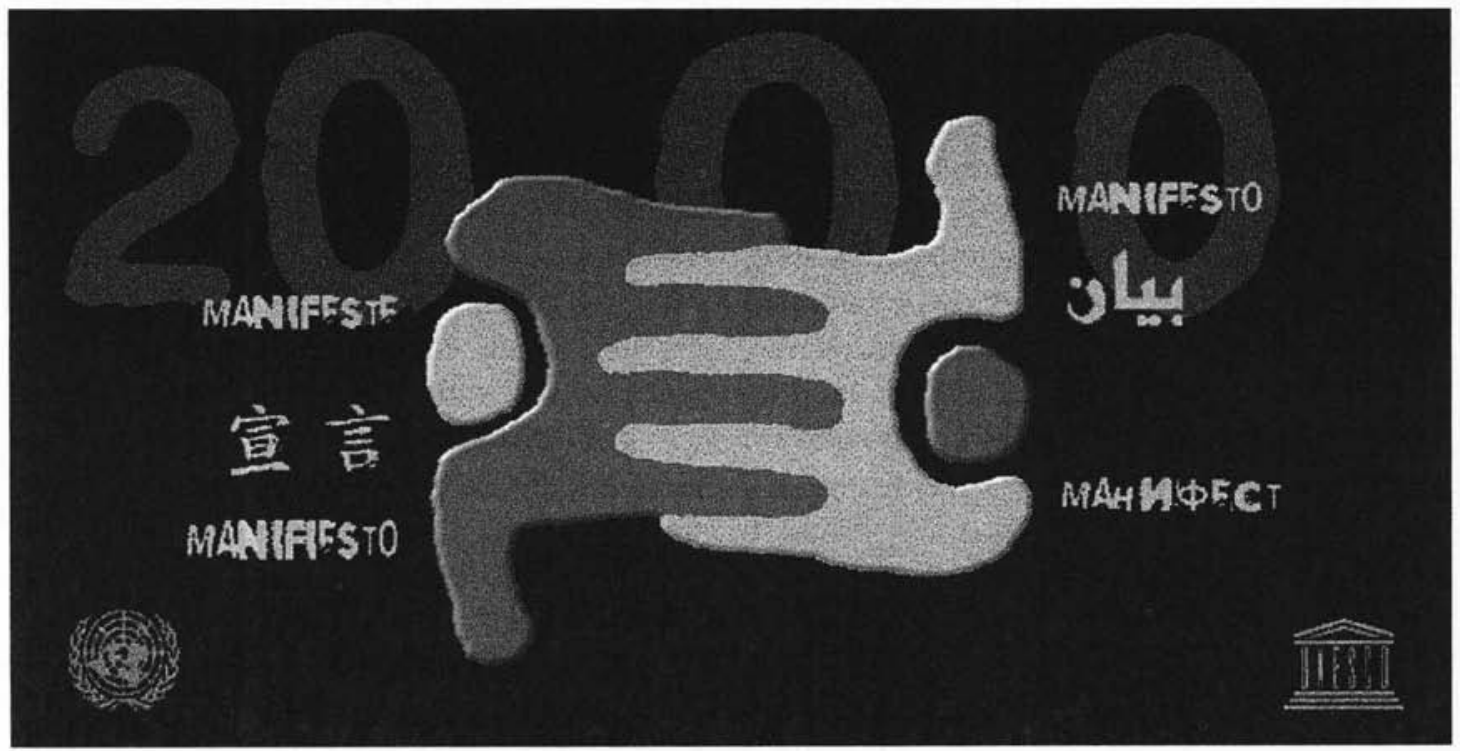

